\title{
Hsp27 reduces glycation-induced toxicity and aggregation of $\alpha$-synuclein
}

\section{Hugo Vicente Miranda ${ }^{{ }^{*} \#}$, Ana Chegão $0^{1^{*}}$, Márcia Oliveira ${ }^{1^{*}}$, Bárbara Fernandes Gomes ${ }^{1}$, Francisco J. Enguita ${ }^{2}$, Tiago Fleming Outeiro ${ }^{1,3,4,5 \#}$}

${ }^{1}$ CEDOC, Chronic Diseases Research Center, NOVA Medical School | Faculdade de Ciências Médicas, Universidade Nova de Lisboa, Campo dos Mártires da Pátria, 130, 1169-056, Lisboa, Portugal; ${ }^{2}$ Instituto de Medicina Molecular, Faculdade de Medicina de Lisboa, Universidade de Lisboa, Lisboa, Portugal; ${ }^{3}$ Department of Experimental Neurodegeneration, Center for Biostructural Imaging of Neurodegeneration, University Medical Center Göttingen, Göttingen, Germany.; ${ }^{4}$ Max Planck Institute for Experimental Medicine, Göttingen, Germany; ${ }^{5}$ Institute of Neuroscience, Medical School, Newcastle University, Framlington Place, Newcastle Upon Tyne, NE2 4HH, UK.

* These authors contributed equally

\# Address correspondence to Tiago F. Outeiro, Experimental Neurodegeneration, Universitätsmedizin Göttingen, Waldweg 33, 37073 Göttingen, Germany. Email: touteir@gwdg.de; CEDOC - Chronic Diseases Research Center, NOVA Medical School, Rua Câmara Pestana no 6, Edifício CEDOC II, 1150-082 Lisboa, Portugal. Email: $\underline{\text { hmvmiranda@nms.unl.pt }}$

\section{Abstract}

a-synuclein (aSyn) is a major player in Parkinson's disease (PD) and a group of other disorders collectively known as synucleinopathies, but the precise molecular mechanisms involved are still unclear. aSyn, as virtually all proteins, undergoes a series of posttranslational modifications (PTMs) during its lifetime which can affect its biology and pathobiology. We recently showed that glycation of aSyn by methylglyoxal (MGO) potentiates its oligomerization and toxicity, induces dopaminergic neuronal cell loss in mice, and affects motor performance in flies. Small heat-shock proteins (sHsps) are molecular chaperones that facilitate the folding of proteins or target misfolded proteins for clearance. Importantly, sHsps were shown to prevent aSyn aggregation and cytotoxicity. Upon treating cells with increasing amounts of methylglyoxal, we found that the levels of Hsp27 decreased in a dose-dependent manner. Therefore, we hypothesized that restoring the levels of Hsp27 in glycating environments could alleviate the pathogenicity of aSyn. Consistently, we found that Hsp27 reduced MGO-induced aSyn aggregation in cells, leading to the formation of non-toxic aSyn species. Remarkably, increasing the levels of Hsp27 suppressed the deleterious effects induced by MGO. Our findings suggest that in glycating environments, the levels of Hsp27 are important for modulating the glycation-associated cellular pathologies in synucleinopathies.

Key words: Parkinson's disease, neurodegeneration, $\alpha$-synuclein, Hsp27, Glycation 


\section{Introduction}

$\alpha$-synuclein (aSyn) is a small protein of 140 amino acid residues abundant in the brain and in various other tissues. In the brain, it is abundant in the presynaptic compartment, but exists also in the nucleus of neurons ${ }^{1-5}$. aSyn is the major component of pathognomonic protein inclusions, known as Lewy bodies and Lewy neurites, present in the brains of patients affected by Parkinson's disease (PD) or dementia with Lewy bodies ${ }^{6-8}$. It is also present in glial cytoplasmic inclusions in multiple system atrophy $(\mathrm{MSA})^{6-8}$. Together, diseases associated with the aggregation of aSyn in the brain are known as synucleinopathies ${ }^{6-10}$. However, the molecular mechanisms underlying aSyn aggregation are still elusive.

aSyn is an intrinsically disordered protein and is prone to aggregation under various conditions ${ }^{11,12}$. The process of aSyn aggregation has been the subject of intensive study, and is thought to proceed through the assembly of the protein into dimers, oligomers, and fibrils, which may then accumulate in protein inclusions ${ }^{9,12-14}$. aSyn undergoes several posttranslational modifications (PTMs) that can modulate its aggregation and cytotoxicity ${ }^{15}$. aSyn is a long-lived protein that while it does not contain any arginine residues, it is lysinerich, making it a preferably target for glycation in the lysine residues ${ }^{16,17}$. Several studies suggest that glycation might be an important contributor to the pathobiology of aSyn ${ }^{17,18}$. In a previous study, we found that aSyn is glycated in the brains of PD patients and that this modification modulates aSyn pathogenicity, contributing to the neurodegenerative process ${ }^{19}$. Furthermore, methylglyoxal (MGO), the strongest glycating agent in living cells, exacerbates aSyn aggregation and toxicity in several models of synucleinopathies, such as yeast, human cells, and animal models of PD ${ }^{19}$. In addition to inducing aSyn oligomerization, MGO also affects the correct clearance of aSyn by impairing the activities of the proteasome and autophagy clearance systems ${ }^{19}$.
The small heat-shock proteins (sHsps) are a family of small molecular weight proteins that are characterized by a highly conserved domain, known as alpha-crystallin domain 20,21. sHsps play an important role in cellular proteostasis ${ }^{22-25}$, in particular by preventing protein aggregation. They act as molecular chaperones, promoting protein folding/refolding, stabilization, and by targeting damaged proteins for degradation ${ }^{24-26}$. Furthermore, sHsps are stress response proteins, upregulated under unfavorable conditions such as heat-shock, metabolic, oxidative, and chemical stress 27,28 . However, sHsps are not only involved in stress responses, but also in stress tolerance, cell death, differentiation, cell cycle, and signal transduction ${ }^{29}$. sHsps have also been reported to play a role in aging and protein aggregation disorders, such as neurodegenerative diseases like Alzheimer's disease and PD 30-34. Remarkably, Hsp27, one of the members of the sHsp family, is present in Lewy bodies ${ }^{35,36}$.

Hsp27 is ubiquitously expressed, at highest levels in the skeletal, smooth, and cardiac muscles ${ }^{37}$. Like other sHsps, it can assemble in smaller oligomers, such as dimers or tetramers, or in large oligomeric complexes ${ }^{38-42}$. Hsp27 is a target of PTMs, such as phosphorylation, which induces the shift in the oligomeric status of Hsp27 ${ }^{40}$. Hsp27 can have different functions, depending on its oligomerization state: in large oligomers, it acts mainly as a molecular chaperone, also exhibiting anti-apoptotic properties ${ }^{42,43}$; in small oligomers, Hsp27 has reduced chaperone activity and acts in the dynamics of microfilaments, contributing to the stabilization of F-actin filaments 44,45 . The role of $\mathrm{Hsp} 27$ in protein aggregation is well documented. The levels of brain Hsp27 brain are increased in the PD brain (cortex) ${ }^{46,47}$, and is also present in Lewy bodies and co-localizes with aSyn ${ }^{35,36}$. In vitro, Hsp27 binds to aSyn preventing aggregation and fibril elongation, and also reducing aSyn cytotoxicity in a concentration-dependent manner $23,35,48-50$. 
Like aSyn, Hsp27 can also be glycated by MGO ${ }^{51-55}$. Interestingly, this modification promotes the formation of large oligomeric complexes of Hsp27, enhancing its chaperone activity and anti-apoptotic properties 51,55 . Moreover, high levels of glucose increase Hsp27 glycation and reduce its levels in a dose dependent manner ${ }^{56}$.

Here, we report that MGO reduces the levels of Hsp27 in a dose dependent manner. Therefore, we hypothesized that restoring the levels of $\mathrm{Hsp} 27$ could prevent glycationassociated aSyn pathobiology. Consistently, Hsp27 overexpression reduced the deleterious effects of MGO in a cellular model of synucleinopathies. Our findings suggest that Hsp27 might constitute an important therapeutic target for modulating glycation-induced pathogenesis of aSyn.

\section{Materials and Methods}

\section{Cell culture}

Human $\mathrm{H} 4$ neuroglioma cells were maintained at $37^{\circ} \mathrm{C}$ in OPTIMEM I (Gibco, Invitrogen, CA, USA) supplemented with $10 \%$ fetal bovine serum (FBS) (Gibco, Invitrogen, CA, USA). H4 neuroglioma cells were seeded in $35 \mathrm{~mm}$ imaging dishes (Ibidi, 170.000 cells/ dish) for immunocytochemistry assays, 12-well plate (TPP, 90.000 cells/ well) for cytotoxicity assays, 6-well plate (TPP, 190.000 cells/ well) for protein analysis, or $6 \mathrm{~cm}$ plates (TPP, 300.000 cells/ dish) for triton-X 100 solubility assay.

\section{Analysis of protein glycation and Hsp27 profile}

H4 neuroglioma naïve cells were plated and treated 24 hours later with increasing amounts of MGO $(0.2 ; 0.5 ; 0.75 ; 1 \mathrm{mM})$, prepared as previously ${ }^{19} .24$ hours after treatment, cells were collected and protein extracts prepared and quantified as previously 19,57 . Protein glycation profile was assessed by western blotting, probing for argpyrimidine (a kind gift from K. Uchida, Laboratory of Food and Biodynamics, Nagoya University Graduate School of Bioagricultural Sciences, Japan) as previously ${ }^{58}$. Hsp27 levels were probed with anti-Hsp27 (F4 1:2000; Santa Cruz Biotechnology, Dallas, TX, USA). Detection procedures were performed according to $\mathrm{ECL}$ system (GE Healthcare, Life Sciences; Little Chalfont, UK), and the signal was detected using a ChemiDoc ${ }^{\mathrm{TM}}$ Imaging Systems (Bio-Rad, Hercules, CA, USA). Densitometry was performed using Image - Image Processing and Analysis in Java. When required, membranes were incubated with stripping solution (250 mM Glycine, $0.1 \%$ of $10 \%$ SDS, pH 2.0) for 45 minutes at room temperature with agitation, followed by 4 washing steps, twice with 1x TBS and twice with 1x TBS supplemented with $10 \%$ Tween 20 solution. Membranes were then incubated with blocking solution for 30 minutes, before reprobing.

\section{Mass spectrometry}

H4 neuroglioma cells protein extracts were separated by SDSPAGE and the correspondent $25 \mathrm{kDa}$ fragment was excised from the gel. Peptide mass fingerprinting analysis was performed as previously ${ }^{19,57}$, in an Applied Biosystems 4700 Proteomics Analyzer with TOF/TOF ion optics. A double miscleavage was allowed, and oxidation of methionyl residues, acetylation of the $\mathrm{N}$-terminal region, and carboxyethylation (CEL) of lysine residues, as well as argpyrimidine or hidroimidazolones formation at arginine residues were assumed as variable modifications. All peaks with S/N 4-5 were included, with a taxonomic restriction to Homo sapiens. The criteria used to accept the identification were significant homology scores achieved in Mascot $(p<0.05)$.

\section{Expression and purification of recombinant aSyn and}

\section{Hsp27}

Human aSyn was expressed and purified as we previously described ${ }^{19}$. SDS-PAGE, followed by western blotting analysis (using standard procedures), confirmed the monomeric 
purification of aSyn (anti-a-synuclein dilution 1:1000; BD Transduction Laboratories ${ }^{\mathrm{TM}}$, San Jose, CA, USA).

For human Hsp27, the E. coli strain BL-21 was transformed by heat shock with HSP27 PET16b construct (a kind gift from Dr. Paul Muchowski) and expression induced for 3 hours with IPTG (0.3 mM). Cells were pelleted and re-suspended in lysis buffer, supplemented with $10 \mathrm{mg} / \mathrm{mL}$ of lysozyme (SigmaAldrich, MO, USA). The cell suspension was then incubated on ice with constant stirring for 20 minutes, followed by the addition of $0.33 \mathrm{~mL} / \mathrm{L}$ benzonase (Sigma-Aldrich, MO, USA), and subsequently incubated at room temperature for 20 minutes with constant stirring. Insoluble cellular debris were removed by centrifugation. $53 \mathrm{~mL} / \mathrm{L}$ of a $200 \mathrm{mM}$ dithiothreitol (Sigma-Aldrich, MO, USA) solution was added to the soluble supernatant, followed by incubation at room temperature with constant stirring for 10 minutes. Insoluble contaminants were removed by centrifugation and the supernatant was filtered with a $0.22 \mu \mathrm{m}$ filter. The sample was loaded into an ion-exchange chromatography $Q$ Sepharose TM fast flow column equilibrated with 20 mM Tris- $\mathrm{HCl}$, pH 8.0. Proteins were eluted with a linear $\mathrm{NaCl}$ gradient $(0-1.0 \mathrm{M})$, at a flow rate of $1.5 \mathrm{~mL} / \mathrm{min}$ and the elution monitored at 280 $\mathrm{nm}$. Protein-containing fractions were collected and probed by SDS-PAGE analysis using Coomassie staining. Fractions containing the Hsp27 were collected, concentrated by centrifugation using Amicon filters and applied to a gel filtration Superdex 75 column, equilibrated with 20 mM Tris$\mathrm{HCl}$ buffer, $\mathrm{pH} 7.4$, containing $100 \mathrm{mM} \mathrm{NaCl}$. Proteins were eluted with the same buffer at a flow rate of $1 \mathrm{~mL} / \mathrm{min}$. Fractions containing Hsp27 were collected and concentrated by centrifugation using Amicon filters. SDS-PAGE, followed by western blotting analysis, confirmed the monomeric purification of Hsp27 (anti-Hsp27 1:2000; Santa Cruz Biotechnology, Dallas, TX, USA).

\section{In vitro aSyn aggregation}

Recombinant monomeric aSyn was diluted at $140 \mu \mathrm{M}$ in 30 $\mathrm{mM}$ Tris- $\mathrm{HCl} \mathrm{pH}$ 7.4. Aggregation was induced as previously described ${ }^{19}$. aSyn aggregation was evaluated alone or in the presence of Hsp27 (0.45 or $3 \mu \mathrm{M})$, and or in the presence of MGO (0.5 mM) or corresponding vehicle.

\section{Thioflavin T binding assay}

The formation of amyloid fibrils was monitored by Thioflavin $\mathrm{T}$ (ThT) binding assay as previously described ${ }^{19}$. Emission wavelength scan at $490 \mathrm{~nm}$ was performed with an excitation wavelength of $450 \mathrm{~nm}$ using a plate reader (Tecan Infinite 200, Männedorf, Switzerland).

\section{Native-PAGE electrophoresis}

$15 \mu \mathrm{g}$ of total protein extract from purified proteins were separated by native electrophoresis using a Tetra cell (BioRad; Hercules, CA, USA), in $12 \%$ polyacrylamide separation gel and a $4 \%$ polyacrylamide stacking gel in non-denaturing conditions, applying a constant voltage of $120 \mathrm{~V}$.

\section{aSyn cytotoxicity assays}

To assess exogenous aSyn toxicity, cells were plated and treated 24 hours later with recombinant aSyn species, either glycated or not, alone or in the presence of Hsp27 (0.45 or 3 $\mu \mathrm{M})$. Cells were collected 24 hours later, and cytotoxicity was determined by LDH cytotoxicity assay (see below).

\section{Hsp27 overexpression}

24h post-seeding, H4 neuroglioma cells were transfected with pcDNA3.1 vectors containing aSyn WT ${ }^{36}$, SynT ${ }^{36}$, or Hsp27 ${ }^{35}$ alone, or co-transfected with aSyn WT and Hsp27, or SynT and Hsp27 pcDNA3.1 vectors, using FuGENE ${ }^{\circledR} 6$ (Roche, Basel, Switzerland), using standard procedures. 20 hours posttransfection, cells were treated with MGO (0.2 mM). 24 hours later, a second MGO treatment $(0.2 \mathrm{mM})$ was performed. Cells were collected for analysis 48 hours post-transfection. 


\section{aSyn, Hsp27 and glycation levels}

H4 protein extracts were analyzed by western-blotting probing for aSyn (anti-a-synuclein dilution 1:1000; BD Transduction Laboratories ${ }^{\mathrm{TM}}$, San Jose, CA, USA), Hsp27 (antiHsp27 F-4 1:2000; Santa Cruz Biotechnology, Dallas, TX, USA), anti-MGO-derived Advanced Glycation and Products (AGEs) (KAL-KH001 Cosmo-Bio, USA, 1:500 dilution) and normalized to $\beta$-actin levels (anti-b-actin 1:5000; Thermo Fisher Scientific; Waltham, MA, USA).

\section{LDH cytotoxicity assay}

Cytotoxicity was measured using lactate dehydrogenase (LDH) kit (Clontech; Mountain View, CA, USA), according to manufacturer's instructions.

\section{Triton-X 100 solubility assay}

The solubility assays were performed as previously described ${ }^{19}$.

\section{Immunocytochemistry}

Immunocytochemistry was performed as previously described ${ }^{19}$. Microscopy images were acquired in a Widefield fluorescent microscope Zeiss Axiovert 40 CFL (Carl Zeiss Microlmaging).

\section{Results}

\section{MGO induces the formation of argpyrimidine modifications and reduces the levels of Hsp27}

First, we determined the profile of argpyrimidine-modified proteins in human $\mathrm{H} 4$ cells induced by increasing concentrations of MGO $(0.2 ; 0.5 ; 0.75 \mathrm{mM})$ after 24 hours of treatment. Argpyrimidine is a specific MGO-derived AGE at arginine residues. We identified a protein migrating with an apparent molecular weight of $\sim 25 \mathrm{kDa}$ (Fig. 1 A). Surprisingly, that signal decreased in an MGO concentration-dependent manner, in contrast to the effect on other proteins (Fig. $1 \mathrm{~A}$ ). To identify this protein, cell extracts were separated by SDSPAGE and the correspondent $\sim 25 \mathrm{kDa}$ fragment was excised from the gel and processed for mass spectrometry analysis, resulting in the identification of Hsp27 (55\% sequence coverage).
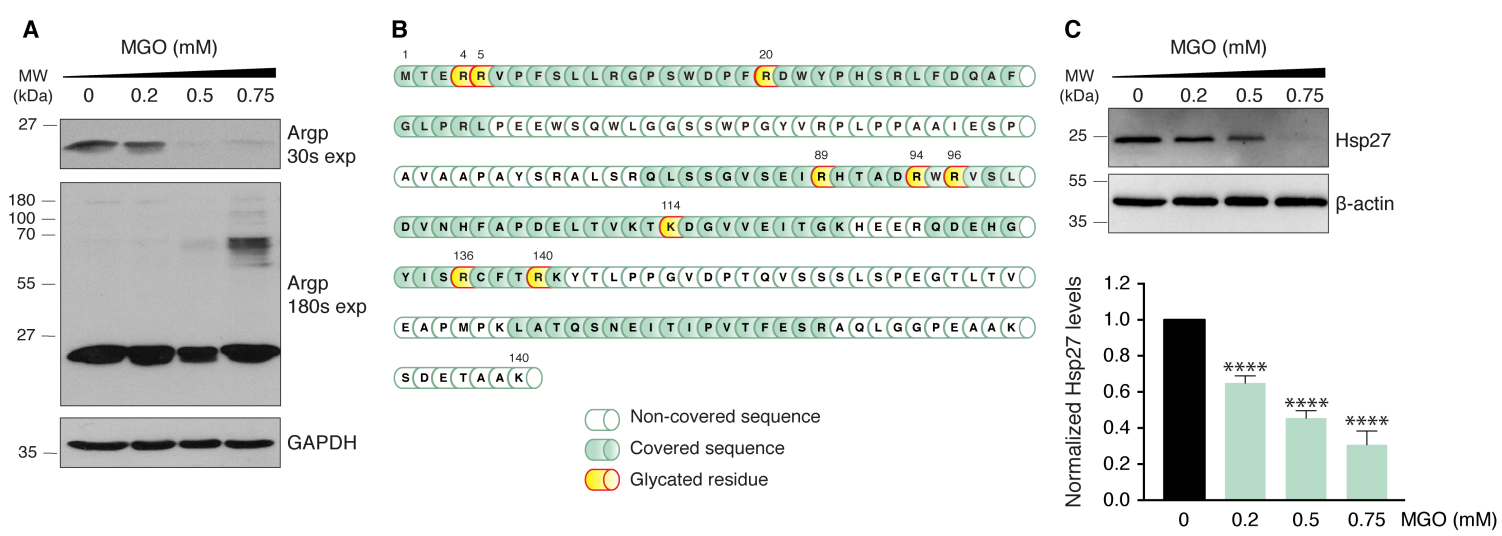

Figure 1 - The levels of Hsp27 decrease in an MGO-dependent manner.

$\mathrm{H} 4$ cells were treated with increasing concentrations of MGO for 24h. (A) Protein extracts were separated by SDS-PAGE and were immunoblotted with anti-Argpyrimidine and anti-GAPDH antibodies (loading control). Two exposure times are shown (30 or 180 seconds of signal acquisition in ChemiDoc ${ }^{\mathrm{TM}}$ Touch Imaging System, Bio-Rad). (B) A gel fragment at $\sim 25 \mathrm{kDa}$ was cut and processed for mass spectrometry analysis, leading to the indentification of Hsp27. Hsp27 schematics show the different glycated residues (yellow), with a 55\% sequence coverage (dark green). (C) Protein extracts were probed for Hsp27 and $\beta$-actin (loading control). Data presented as fold ratio to vehicle-treated cells (n=3). ${ }^{* * * *} p<0.0001$, oneway ANOVA, followed by Tukey's multiple comparisons test. 
We identified several glycated residues in Hsp27, mainly in arginine residues (Fig. $1 B$ and Supplemental table 1 ), and immunoblot analysis confirmed that the $\sim 25 \mathrm{kDa}$ protein was recognized by an antibody specific for Hsp27. Interestingly, we confirmed that the levels of Hsp27 decreased in cells treated with increasing concentrations of MGO (Fig. $1 \mathrm{C}$ ).

\section{Hsp27 reduces aSyn aggregation and cytotoxicity}

Hsp27 was previously shown to reduce the oligomerization of aSyn ${ }^{59}$. However, the effect of Hsp27 on the oligomerization of glycated aSyn has not been investigated. To address this, we tested the effect of sub-stoichiometric levels of Hsp27 (300:1 or 300:7, aSyn:Hsp27) on aSyn aggregation (140 $\mu \mathrm{M})$, in the presence or absence of glycation conditions. To study the kinetics of aggregation, aSyn was incubated under controlled temperature and shaking conditions, and samples were collected at specific timepoints. Using native-PAGE electrophoresis followed by immunoblot analysis, we observed that, with time, aSyn species appeared at the top of the gel (Fig. 2 A), indicating the formation of high molecular weight (HMW) species ${ }^{60-64}$. In the presence of Hsp27, the formation of these HMW species was reduced (Fig. 2 A).

As we and others previously reported that while suppressing fibril formation, glycation of aSyn by MGO increases its oligomerization ${ }^{19,65}$. Here, we evaluated if Hsp27 protects from glycation effects on aSyn oligomerization and found that it reduced the formation of HMW species of aSyn (Fig. 2 B).
A

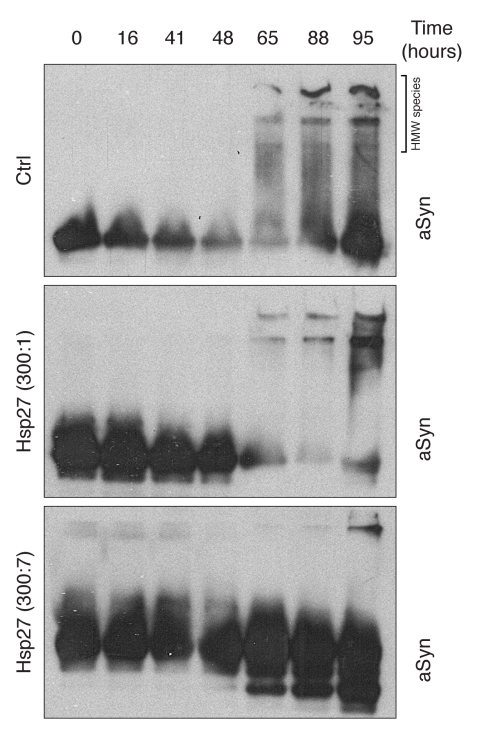

B

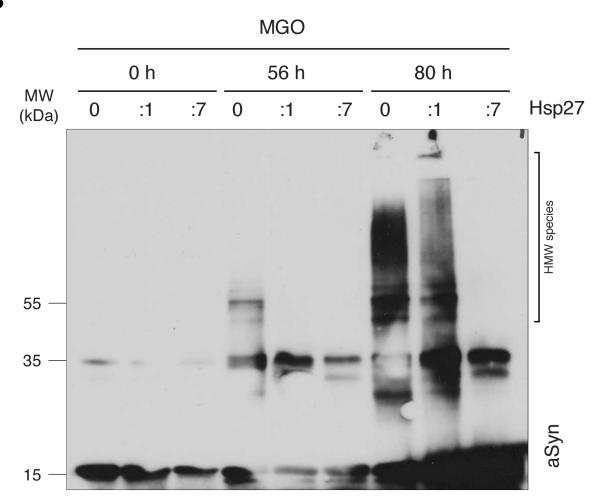

C
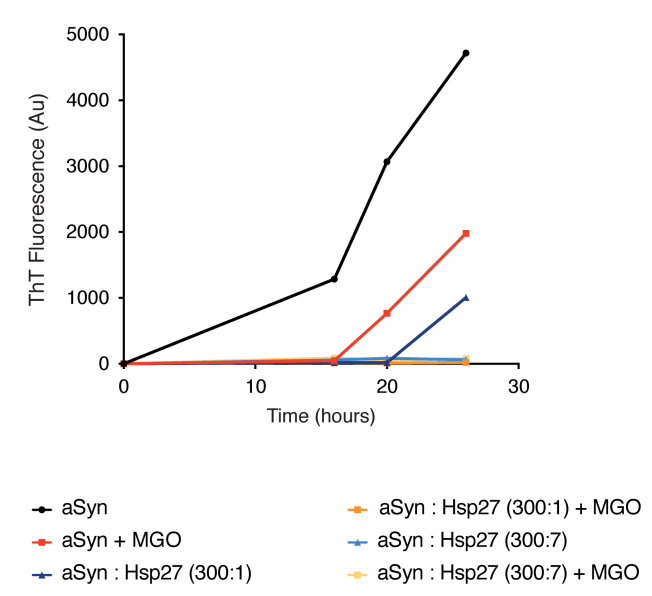

D

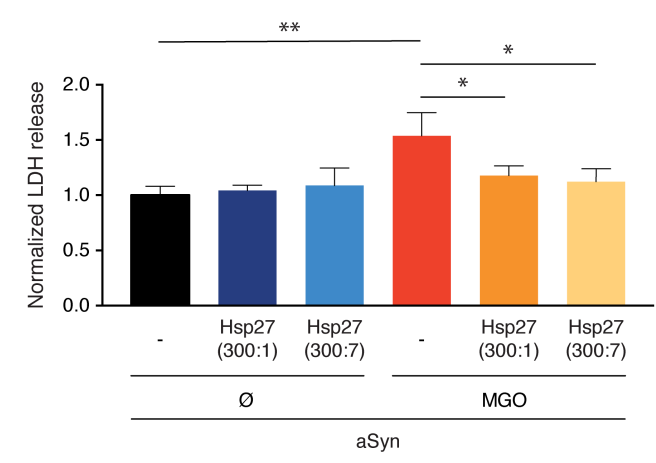

Figure 2 - Hsp27 decreases aSyn aggregation and toxicity in a dose dependent manner.

aSyn aggregation kinetics (140 $\mu \mathrm{M})$ in the absence or presence of Hsp27 (300:1 or 300:7, aSyn:Hsp27) was evaluated by $(A)$ native-PAGE followed by immunoblotting with an anti-aSyn antibody. (B) SDS-PAGE followed by immunoblotting with an anti-aSyn antibody, in control or MGO-glycation conditions. (C) ThT aggregation assays. (D) The cytotoxicity of the resulting species was evaluated in $\mathrm{H} 4$ cells using LDH release as a readout. Data normalized to control conditions without Hsp27 or MGO (n=3). * $p<$ $0.05, * * p<0.01$, one-way ANOVA, followed by Tukey's multiple comparisons test. 
In particular, at a 300:7 (aSyn:Hsp27) molar ratio, aSyn remains mainly monomeric or as lower molecular weight species, suppressing the formation of HMW species, even at $80 \mathrm{~h}$ of incubation. We also confirmed a reduction in the formation of aSyn amyloid structures in the presence of Hsp27, using Thioflavin T (ThT) as a readout (Fig. 2 C).

Next, to determine whether Hsp27 affected the toxicity of glycated aSyn species, we exposed $\mathrm{H} 4$ cells to those species, for $24 \mathrm{~h}$, and assessed the overall membrane integrity (LDH assay) as a readout of cytotoxicity. While aSyn exposed to MGO was toxic, as we have previously shown, the species incubated with Hsp27 were not (Fig. 2 D).
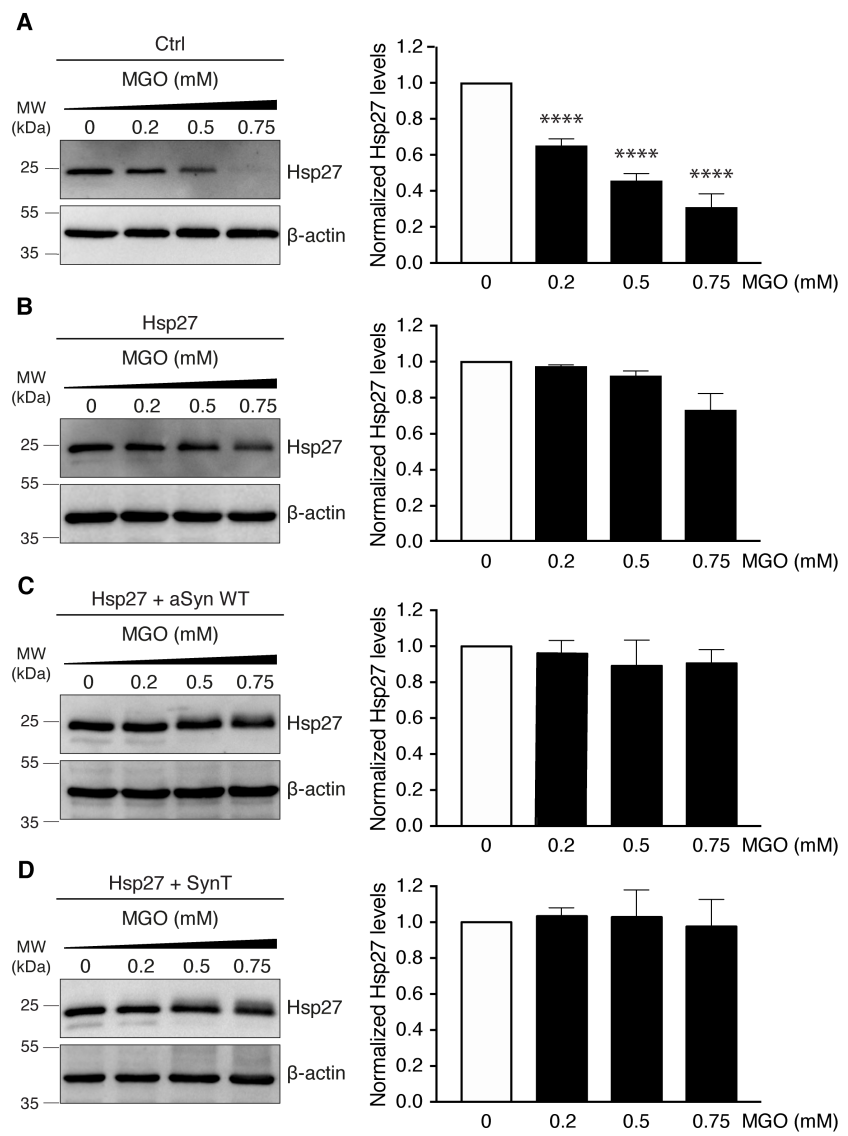

\section{Hsp27 reduces MGO-associated aSyn pathobiology in cellular models}

Next, we investigated the effects of Hsp27 on MGOassociated aSyn cellular pathologies in cells. Briefly, cells expressing aSyn alone or together with Hsp27 were treated with MGO 20 hours post-transfection, and then received a second treatment 24 hours later, in order to ensure glycation conditions were maintained. Protein extracts were then prepared and analyzed by immunoblot analyses. In contrast to the effect of MGO observed on the endogenous levels of Hsp27 (Fig. 1), we found that in cells overexpressing Hsp27 the levels did not decrease (Fig. 3 A-D), while the general

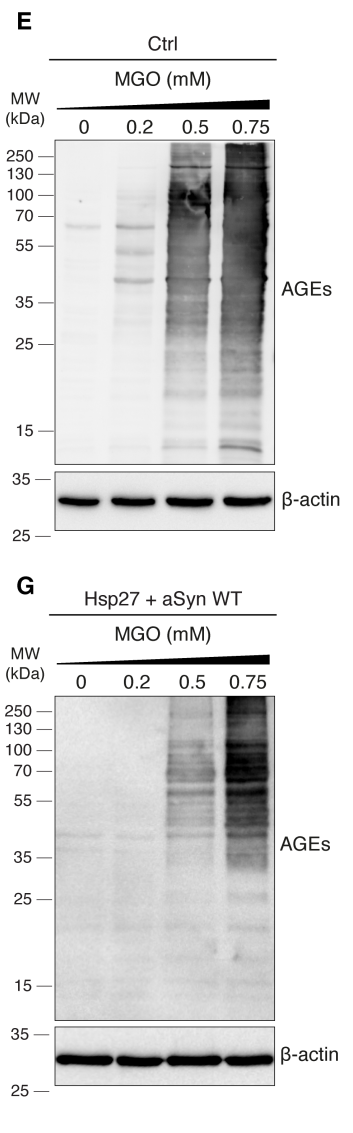

Figure 3 - Hsp27 overexpression compensates for MGO-induced decrease of Hsp27 levels.

$\mathrm{H} 4$ cells were treated with increasing concentrations of MGO for $24 \mathrm{~h}$. Protein extracts from $(A, E)$ naïve cells; or from cells overexpressing $(B, F)$ Hsp27; $(C, G)$ Hsp27 and aSyn; or $(D, H)$ Hsp27 and SynT, were separated by SDS-PAGE and immunoblotted for Hsp27 (A-D) or AGEs (E-H) and anti- $\beta$-actin antibodies (loading control). For $(A-D)$ data is presented as Hsp27 normalized levels to vehicle-treated cells. Panel $(A)$ is repeated from main Fig. $1 C$. ${ }^{* * *} p<0.0001$, one-way ANOVA, followed by Tukey's multiple comparisons test. 
A
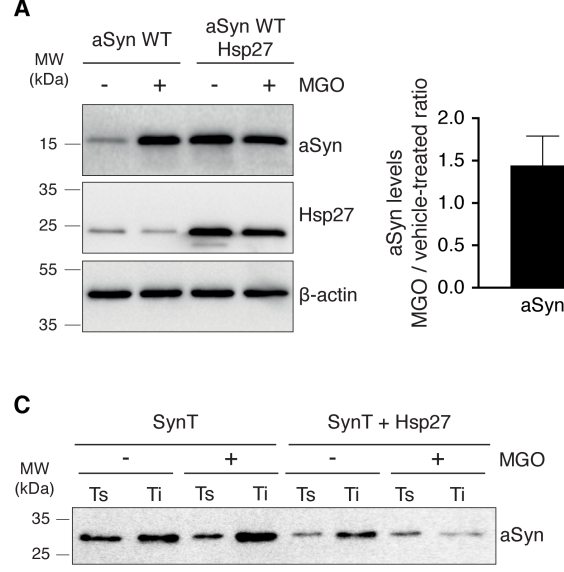

E

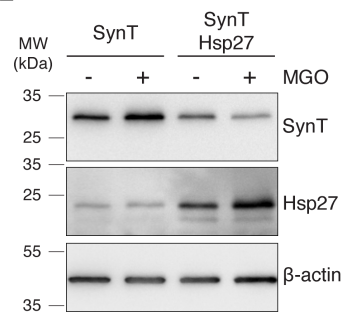

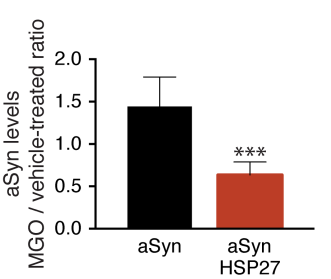

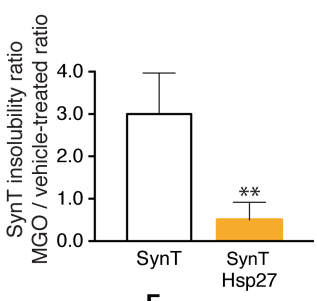

$\mathbf{F}$
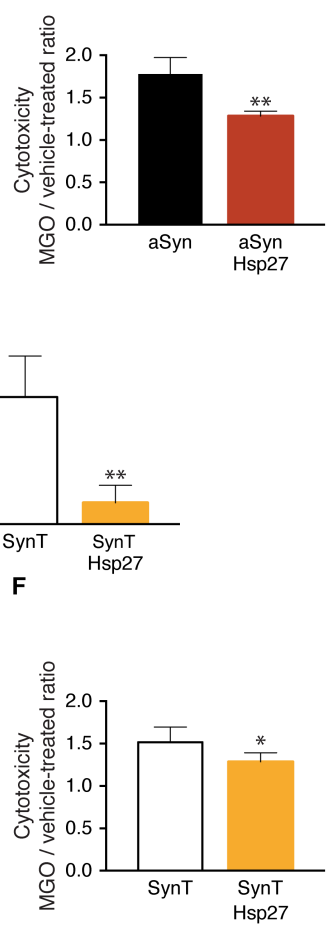
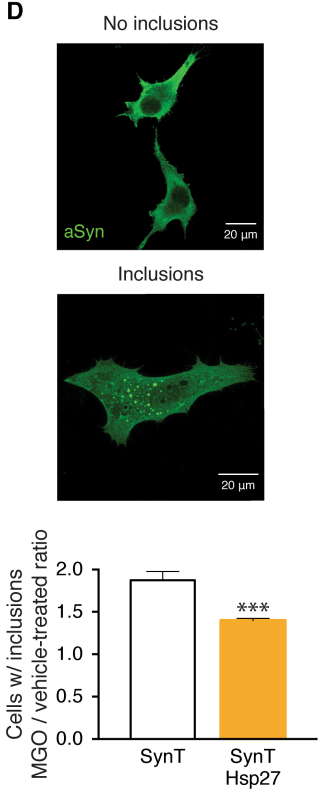

Figure 4 - Hsp27 overexpression reduces cytotoxicity, insolubility and aggregation of aSyn in glycating conditions.

Cells expressing aSyn or SynT, or co-expressing aSyn or SynT together with Hsp27 were treated 2 times for 2 consecutive periods of $24 \mathrm{~h}$ with vehicle or MGO (0.2mM). (A) Protein levels of cells expressing aSyn were determined by immunoblotting with anti-aSyn, -Hsp27 or - $\beta$-actin antibodies. (B) Cytotoxicity was determined by loss of membrane integrity (LDH release). (C) Triton ${ }^{\mathrm{TM}} \mathrm{X}-100$ soluble and insoluble (TS and TI) fractions were probed for a-synuclein. The ratio between soluble and insoluble fractions is normalized to vehicle-treated ratio and presented as SynT insolubility $(n=4)$. (D) Cells were processed for immunocytochemistry (aSyn, green), and the percentage of cells with inclusions determined. $(E)$ Protein levels and $(F)$ cytotoxicity of cells expressing SynT were determined as in $(A)$ and $(B)$. Data presented as fold ratio between MGO and vehicle-treated cells, at least $\mathrm{n}=3 .{ }^{*} p<0.05, * * p<0.01, * * * p<0.001$ unpaired t-test with equal SD.

glycation increased in an MGO-dependent manner (Fig. 3 EH). In cells expressing aSyn WT, we observed that Hsp27 prevented aSyn cytotoxicity by 10\%. Impressively, Hsp27 overexpression also prevented the MGO-associated increase of aSyn levels ( 56\%) (Fig. 4 A) and cytotoxicity ( 28\%) (Fig. 4 B).

In order to assess whether Hsp27 modulated the MGOinduced aggregation of aSyn, we used an established cell model using an aggregation-prone variant of aSyn (known as SynT) ${ }^{19,64,66-68}$. This model consists of a modified form of aSyn where the C-terminus is fused to a truncated, non-fluorescent fragment of GFP (known as SynT) ${ }^{36},{ }^{69}$. Using this model, we have previously shown that MGO-treatment of cells expressing SynT increases the percentage of cells with aSyn inclusions (51\% to $85 \%)^{19}$. The aggregation status of SynT was assessed using Triton $^{\mathrm{TM}} \mathrm{X}-100$ solubility assays ${ }^{19}$. Briefly, H4 cells overexpressing i) SynT; or ii) SynT together with Hsp27, were treated with MGO as previously described. Protein extraction was performed in non-denaturing conditions, and protein extracts solubilized in $1 \%$ of $\operatorname{Triton}^{\mathrm{TM}} \mathrm{X}-100$. Soluble and insoluble fractions were separated by centrifugation and analyzed by western blot. We observed that MGO treatment induced an increase of SynT insolubility (Fig. 4 C). Remarkably, Hsp27 expression not only prevented SynT insolubility, but 
also potentiated its solubility in comparison to control conditions (Fig. 4 C). SynT aggregation was also assessed by immunocytochemistry, as previously described ${ }^{19,66}$. Using the same paradigm, $\mathrm{H} 4$ cells were stained for aSyn and the percentage of cells with aggregates determined. Consistently, Hsp27 expression prevented the MGO-induced SynT aggregation ( 25\%) (Fig. 4 D). In cells overexpressing SynT, we observed that Hsp27 was also able to prevent the MGOassociated increase of SynT levels ( 59\%) (Fig. 4 E) and cytotoxicity ( 16\%) (Fig. 4 F).

\section{Discussion}

Recent reports suggest that type II diabetes is an important risk factor for PD. In particular, protein glycation seems to play an important role in synucleinopathies ${ }^{16-18}$. We previously showed that aSyn is a target of glycation, which potentiates its oligomerization, impairs its clearance and membrane binding ability, resulting in its accumulation, aggregation and cytotoxicity, inducing dopaminergic neuronal loss and motor impairments in animal models ${ }^{19}$.

However, glycation can affect many other proteins in addition to aSyn, thereby contributing to a variety of cellular pathologies. To investigate this, we evaluated the pattern of glycation in a cellular model of synucleinopathies treated with increasing concentrations of MGO, as a model glycating agent since it is the most significant and highly reactive glycating agent in cells, mainly generated as a by-product of glycolysis 70. Surprisingly, although we were expecting an overall increase in the levels of glycated proteins, we observed dominant signal corresponding to a $\sim 25 \mathrm{kDa}$ protein whose levels decreased with increased levels of MGO. Using peptide mass fingerprinting we identified this protein as $\mathrm{Hsp} 27$ and confirmed this using a specific antibody. In fact, we found that the total levels of Hsp27 decreased in an MGO-dependent manner.
Hsp27 was previously shown to be protective in models of synucleinopathies. In particular, it reduces aSyn oligomerization ${ }^{23,49,71}$ and prevents the toxicity of exogenous aSyn species in neuronal cells ${ }^{23,50}$. Hsp27 reduces the aggregation of aSyn ${ }^{35}$ and of other proteins associated with other neurodegenerative disorders ${ }^{33,72-74}$. Therefore, we hypothesized that under glycating conditions, restoring or inducing the levels of Hsp27 might prevent the deleterious effects of cellular glycation in aSyn patohogenesis.

To test our hypothesis, we first compared the kinetics of recombinant aSyn oligomerization alone or in the presence of Hsp27, in control or glycating conditions. In contrast to other studies that tested aSyn:Hsp27 ratios of $1: 1$ or $5: 1^{23,49}$, we performed our analysis in sub-stochiometric concentrations of 300:1 or 300:7, to assess the effect of much lower amounts of Hsp27, We confirmed our previous findings that glycation potentiates aSyn oligomerization. Moreover, we also validated that Hsp27 is able to reduce non-glycated aSyn aggregation. Remarkably, in the presence of Hsp27, the deleterious effects of glycation over aSyn oligomerization were almost completely abolished, avoiding the formation of stable HMW species. Also, although glycated aSyn species are cytotoxic, the species formed in the presence of Hsp27 were not. These findings provide important evidence that Hsp27 may directly suppress the pathogenicity of aSyn-glycation.

In order to further validate our hypothesis, we evaluated if Hsp27 overexpression would be protective in cell models of aSyn toxicity and aggregation. Impressively, Hsp27 alleviated the MGO-induced pathogenic phenotypes, reducing cytotoxicity in cells expressing WT aSyn or an aggregationprone version of aSyn (SynT). Hsp27 significantly reduced the levels of aSyn or SynT and reduced the aggregation of aSyn. Notably, the cytotoxic protection provided by Hsp27 in glycation conditions (28\%) is higher than in non-glycation conditions (10\%), suggesting a relevant role of Hsp27 in glycation conditions. Interestingly, MGO was shown to modify 
A

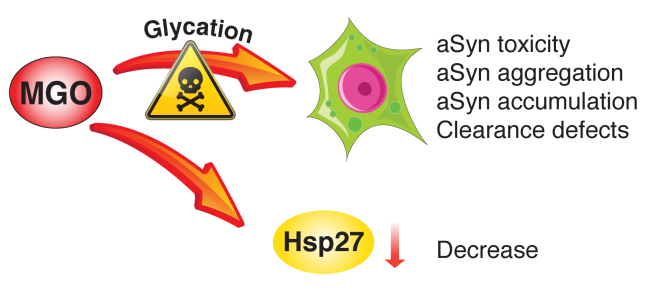

B

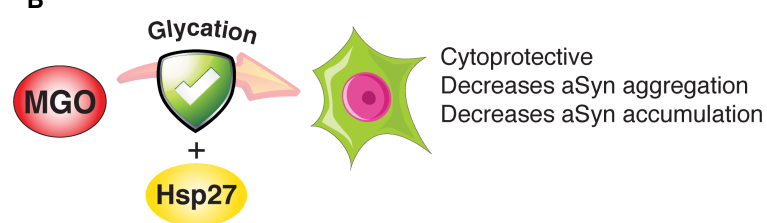

C Toxicity

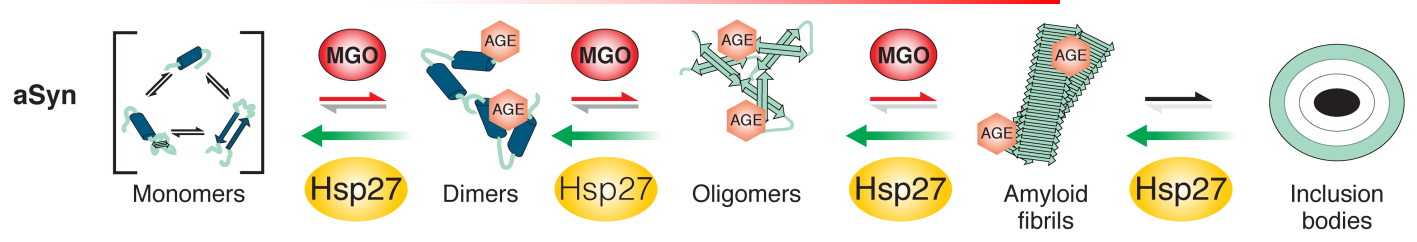

Figure 5 - Model for the effects of Hsp27 on aSyn aggregation.

(A) MGO-induced glycation exacerbates aSyn pathogenicity. Here, we showed that the levels of Hsp27 decrease in an MGO dependent manner.

(B) Restoring Hsp27 expression prevents the deleterious effects of glycation in a cellular model of synucleinopathies, reducing aggregation both in vitro and in cells. $(C)$ Based on our aSyn aggregation studies, we hypothesize that Hsp27 might reduce the oligomerization of aSyn and, therefore, its toxicity.

the $\alpha$-crystallin domain of Hsps (namely, Hsp27) probably by exposing hydrophobic sites that would, otherwise, not be available for chaperone function. In addition, MGO might induce the formation of large oligomers of Hsp27, enhancing its activity ${ }^{51,75}$. This enhanced $\mathrm{Hsp} 27$ activity might be responsible for reducing aSyn cytotoxicity, by reducing the formation of aSyn oligomers, or by preventing apoptosis, since Hsp27 glycation potentiates its anti-apoptotic potential, as described in several types of cancers ${ }^{54,55,76}$. Although in the present study we could not confirm the formation of large oligomeric species of Hsp27, we hypothesize that the strong reduction of Hsp27 protein levels would prevail over a possible gain-of-function of Hsp27 as a molecular chaperone. The presence of Hsp27 in Lewy bodies suggests it may play a relevant role in $\mathrm{PD}{ }^{77,78}$. Actually, a decrease in the activity of Hsps and of other protein quality control components is associated with ageing and neurodegeneration 79,80. Molecular chaperones are crucial for stabilising protein conformations and for directing misfolded or damaged proteins for degradation by the different clearance pathways.
Therefore, our work highlights the importance of Hsp27 in suppressing the pathological conditions induced by glycation (Fig. 5) and suggests that Hsp27 may constitute a suitable target for intervention in synucleinopathies and other neurodegenerative disorders.

\section{Acknowledgments}

This study was supported by Fundação para a Ciência e Tecnologia (FCT) PTDC/NEU-OSD/5644/2014 and EXPL/NEUOSD/0606/2012. Authors were supported by: HVM (FCT, SFRH/BPD/109347/2015); MO (FCT, EXPL/NEUOSD/0606/2012); AC (FCT, PD/BD/136863/2018; ProRegeM PhD programme, mechanisms of disease and regenerative medicine); BFG (PTDC/NEU-OSD/5644/2014). TFO is supported an EU Joint Programme - Neurodegenerative Disease Research (JPND) project (aSynProtec). The project is supported through the following funding organisations under the aegis of JPND - www.jpnd.edu (BMBF). 


\section{Author Contributions}

$H$. Vicente Miranda and T.F. Outeiro designed research; $H$. Vicente Miranda, A. Chegão, M. Oliveira and B.F. Gomes performed research; F.J. Enguita contributed new reagents or analytic tools; H. Vicente Miranda, A. Chegão, M. Oliveira and T.F. Outeiro analyzed data; H. Vicente Miranda, A. Chegão and T.F. Outeiro wrote the manuscript.

\section{References}

1. Maroteaux, L., Campanelli, J. T. \& Scheller, R. H. Synuclein: a neuron-specific protein localized to the nucleus and presynaptic nerve terminal. The Journal of neuroscience : the official journal of the Society for Neuroscience 8, 2804-2815 (1988).

2. Iwai, A. et al. The precursor protein of non-A beta component of Alzheimer's disease amyloid is a presynaptic protein of the central nervous system. Neuron 14, 467-475 (1995).

3. McLean, P. J., Ribich, S. \& Hyman, B. T. Subcellular localization of alpha-synuclein in primary neuronal cultures: effect of missense mutations. Journal of neural transmission. Supplementum, 53-63 (2000).

4. Goncalves, S. \& Outeiro, T. F. Assessing the subcellular dynamics of alpha-synuclein using photoactivation microscopy. Molecular neurobiology 47, 1081-1092, doi:10.1007/s12035-013-8406-x (2013).

5. Pinho, R. et al. Nuclear localization and phosphorylation modulate pathological effects of alpha-synuclein. Human molecular genetics 28, 31-50, doi:10.1093/hmg/ddy326 (2019).

6. Spillantini, M. G. et al. Filamentous alpha-synuclein inclusions link multiple system atrophy with Parkinson's disease and dementia with Lewy bodies. Neuroscience letters 251, 205-208 (1998).

7. Spillantini, M. G., Crowther, R. A., Jakes, R., Hasegawa, M. \& Goedert, M. alpha-Synuclein in filamentous inclusions of
Lewy bodies from Parkinson's disease and dementia with lewy bodies. Proceedings of the National Academy of Sciences of the United States of America 95, 6469-6473 (1998).

8. Spillantini, M. G. et al. Alpha-synuclein in Lewy bodies. Nature 388, 839-840, doi:10.1038/42166 (1997).

9. Vekrellis, K., Xilouri, M., Emmanouilidou, E., Rideout, H. J. \& Stefanis, L. Pathological roles of alpha-synuclein in neurological disorders. The Lancet. Neurology 10, 1015-1025, doi:10.1016/s1474-4422(11)70213-7 (2011).

10. Shachar, T. et al. Lysosomal storage disorders and Parkinson's disease: Gaucher disease and beyond. Mov Disord 26, 1593-1604, doi:10.1002/mds.23774 (2011).

11. Weinreb, P. H., Zhen, W., Poon, A. W., Conway, K. A. \& Lansbury, P. T., Jr. NACP, a protein implicated in Alzheimer's disease and learning, is natively unfolded. Biochemistry 35, 13709-13715, doi:10.1021/bi961799n (1996).

12. Soto, C. Unfolding the role of protein misfolding in neurodegenerative diseases. Nature reviews. Neuroscience 4, 49-60, doi:10.1038/nrn1007 (2003).

13. Gadad, B. S., Britton, G. B. \& Rao, K. S. Targeting oligomers in neurodegenerative disorders: lessons from alphasynuclein, tau, and amyloid-beta peptide. Journal of Alzheimer's disease : JAD 24 Suppl 2, 223-232, doi:10.3233/jad-2011-110182 (2011).

14. Michel, P. P., Hirsch, E. C. \& Hunot, S. Understanding Dopaminergic Cell Death Pathways in Parkinson Disease. Neuron 90, 675-691, doi:10.1016/j.neuron.2016.03.038 (2016).

15. Wales, P., Pinho, R., Lazaro, D. F. \& Outeiro, T. F. Limelight on alpha-synuclein: pathological and mechanistic implications in neurodegeneration. Journal of Parkinson's disease 3, 415459, doi:10.3233/JPD-130216 (2013).

16. Vicente Miranda, H. \& Outeiro, T. F. The sour side of neurodegenerative disorders: the effects of protein glycation. The Journal of pathology 221, 13-25, doi:10.1002/path.2682 (2010). 
17. Vicente Miranda, H., El-Agnaf, O. M. \& Outeiro, T. F. Glycation in Parkinson's disease and Alzheimer's disease. Mov Disord 31, 782-790, doi:10.1002/mds.26566 (2016).

18. Konig, A., Vicente Miranda, H. \& Outeiro, T. F. AlphaSynuclein Glycation and the Action of Anti-Diabetic Agents in Parkinson's Disease. Journal of Parkinson's disease 8, 33-43, doi:10.3233/JPD-171285 (2018).

19. Vicente Miranda, H. et al. Glycation potentiates alphasynuclein-associated neurodegeneration

in synucleinopathies. Brain 140, 1399-1419, doi:10.1093/brain/awx056 (2017).

20. Stamler, R., Kappe, G., Boelens, W. \& Slingsby, C. Wrapping the alpha-crystallin domain fold in a chaperone assembly. Journal of molecular biology 353, 68-79, doi:10.1016/j.jmb.2005.08.025 (2005).

21. van Montfort, R. L., Basha, E., Friedrich, K. L., Slingsby, C. \& Vierling, E. Crystal structure and assembly of a eukaryotic small heat shock protein. Nature structural biology 8, 10251030, doi:10.1038/nsb722 (2001).

22. Cox, D. \& Ecroyd, H. The small heat shock proteins alphaBcrystallin (HSPB5) and Hsp27 (HSPB1) inhibit the intracellular aggregation of alpha-synuclein. Cell stress \& chaperones 22, 589-600, doi:10.1007/s12192-017-0785-x (2017).

23. Cox, D. et al. The small heat shock protein Hsp27 binds alpha-synuclein fibrils, preventing elongation and cytotoxicity. J Biol Chem 293, 4486-4497, doi:10.1074/jbc.M117.813865 (2018).

24. Hartl, F. U., Bracher, A. \& Hayer-Hartl, M. Molecular chaperones in protein folding and proteostasis. Nature 475, 324-332, doi:10.1038/nature10317 (2011).

25. Treweek, T. M., Meehan, S., Ecroyd, H. \& Carver, J. A. Small heat-shock proteins: important players in regulating cellular proteostasis. Cellular and molecular life sciences : CMLS 72, 429-451, doi:10.1007/s00018-014-1754-5 (2015).
26. Saibil, H. Chaperone machines for protein folding, unfolding and disaggregation. Nature reviews. Molecular cell biology 14, 630-642, doi:10.1038/nrm3658 (2013).

27. Bartelt-Kirbach, B. \& Golenhofen, N. Reaction of small heat-shock proteins to different kinds of cellular stress in cultured rat hippocampal neurons. Cell stress \& chaperones 19, 145-153, doi:10.1007/s12192-013-0452-9 (2014).

28. Mehlen, P., Mehlen, A., Godet, J. \& Arrigo, A. P. hsp27 as a switch between differentiation and apoptosis in murine embryonic stem cells. J Biol Chem 272, 31657-31665 (1997).

29. Carra, S. et al. The growing world of small heat shock proteins: from structure to functions. Cell stress \& chaperones 22, 601-611, doi:10.1007/s12192-017-0787-8 (2017).

30. Schultz, C. et al. Expression of stress proteins alpha Bcrystallin, ubiquitin, and hsp27 in pallido-nigral spheroids of aged rhesus monkeys. Neurobiology of aging 22, 677-682 (2001).

31. Braak, H., Del Tredici, K., Sandmann-Kiel, D., Rub, U. \& Schultz, C. Nerve cells expressing heat-shock proteins in Parkinson's disease. Acta neuropathologica 102, 449-454 (2001).

32. Bjorkdahl, C. et al. Small heat shock proteins Hsp27 or alphaB-crystallin and the protein components of neurofibrillary tangles: tau and neurofilaments. Journal of neuroscience research 86, 1343-1352, doi:10.1002/jnr.21589 (2008).

33. Wilhelmus, M. M. et al. Small heat shock proteins inhibit amyloid-beta protein aggregation and cerebrovascular amyloid-beta protein toxicity. Brain Res 1089, 67-78, doi:10.1016/j.brainres.2006.03.058 (2006).

34. Walther, D. M. et al. Widespread Proteome Remodeling and Aggregation in Aging C. elegans. Cell 161, 919-932, doi:10.1016/j.cell.2015.03.032 (2015).

35. Outeiro, T. F. et al. Small heat shock proteins protect against alpha-synuclein-induced toxicity and aggregation. 
Biochemical and biophysical research communications 351, 631-638, doi:10.1016/j.bbrc.2006.10.085 (2006).

36. McLean, P. J., Kawamata, H. \& Hyman, B. T. Alphasynuclein-enhanced green fluorescent protein fusion proteins form proteasome sensitive inclusions in primary neurons. Neuroscience 104, 901-912 (2001).

37. Sugiyama, Y. et al. Muscle develops a specific form of small heat shock protein complex composed of MKBP/HSPB2 and HSPB3 during myogenic differentiation. J Biol Chem 275, 1095-1104 (2000).

38. Mehlen, P., Hickey, E., Weber, L. A. \& Arrigo, A. P. Large unphosphorylated aggregates as the active form of hsp27 which controls intracellular reactive oxygen species and glutathione levels and generates a protection against TNFalpha in NIH-3T3-ras cells. Biochemical and biophysical research communications 241, 187-192, doi:10.1006/bbrc.1997.7635 (1997).

39. Mymrikov, E. V., Bukach, O. V., Seit-Nebi, A. S. \& Gusev, N. B. The pivotal role of the beta 7 strand in the intersubunit contacts of different human small heat shock proteins. Cell stress \& chaperones 15, 365-377, doi:10.1007/s12192-0090151-8 (2010).

40. Rogalla, T. et al. Regulation of Hsp27 oligomerization, chaperone function, and protective activity against oxidative stress/tumor necrosis factor alpha by phosphorylation. J Biol Chem 274, 18947-18956 (1999).

41. Arrigo, A. P. \& Pauli, D. Characterization of HSP27 and three immunologically related polypeptides during Drosophila development. Experimental cell research 175, 169 183 (1988).

42. Abisambra, J. F. et al. Phosphorylation dynamics regulate Hsp27-mediated rescue of neuronal plasticity deficits in tau transgenic mice. The Journal of neuroscience : the official journal of the Society for Neuroscience 30, 15374-15382, doi:10.1523/jneurosci.3155-10.2010 (2010).
43. Paul, C. et al. Dynamic processes that reflect antiapoptotic strategies set up by HspB1 (Hsp27). Experimental cell research 316, 1535-1552, doi:10.1016/j.yexcr.2010.03.006 (2010).

44. Guay, J. et al. Regulation of actin filament dynamics by p38 map kinase-mediated phosphorylation of heat shock protein 27. Journal of cell science 110 ( Pt 3), 357-368 (1997). 45. Lavoie, J. N., Hickey, E., Weber, L. A. \& Landry, J. Modulation of actin microfilament dynamics and fluid phase pinocytosis by phosphorylation of heat shock protein 27. J Biol Chem 268, 24210-24214 (1993).

46. Renkawek, K., Bosman, G. J. \& de Jong, W. W. Expression of small heat-shock protein hsp 27 in reactive gliosis in Alzheimer disease and other types of dementia. Acta neuropathologica 87, 511-519 (1994).

47. Renkawek, K., Stege, G. J. \& Bosman, G. J. Dementia, gliosis and expression of the small heat shock proteins hsp27 and alpha B-crystallin in Parkinson's disease. Neuroreport 10, 2273-2276 (1999).

48. Cox, D., Selig, E., Griffin, M. D., Carver, J. A. \& Ecroyd, H. Small Heat-shock Proteins Prevent alpha-Synuclein Aggregation via Transient Interactions and Their Efficacy Is Affected by the Rate of Aggregation. J Biol Chem 291, 2261822629, doi:10.1074/jbc.M116.739250 (2016).

49. Bruinsma, I. B. et al. Inhibition of alpha-synuclein aggregation by small heat shock proteins. Proteins 79, 29562967, doi:10.1002/prot.23152 (2011).

50. Zourlidou, A., Payne Smith, M. D. \& Latchman, D. S. HSP27 but not HSP70 has a potent protective effect against alphasynuclein-induced cell death in mammalian neuronal cells. Journal of neurochemistry 88, 1439-1448 (2004).

51. Nagaraj, R. H. et al. Enhancement of chaperone function of alpha-crystallin by methylglyoxal modification. Biochemistry 42, 10746-10755, doi:10.1021/bi034541n (2003). 
52. Schalkwijk, C. G. et al. Heat-shock protein 27 is a major methylglyoxal-modified protein in endothelial cells. FEBS letters 580, 1565-1570, doi:10.1016/j.febslet.2006.01.086 (2006).

53. Padival, A. K., Crabb, J. W. \& Nagaraj, R. H. Methylglyoxal modifies heat shock protein 27 in glomerular mesangial cells. FEBS letters 551, 113-118 (2003).

54. Oya-Ito, T. et al. Heat-shock protein 27 (Hsp27) as a target of methylglyoxal in gastrointestinal cancer. Biochimica et $\begin{array}{llll}\text { biophysica } & \text { acta 1812, }\end{array}$ doi:10.1016/j.bbadis.2011.03.017 (2011).

55. Sakamoto, H., Mashima, T., Yamamoto, K. \& Tsuruo, T. Modulation of heat-shock protein 27 (Hsp27) anti-apoptotic activity by methylglyoxal modification. J Biol Chem 277, 45770-45775, doi:10.1074/jbc.M207485200 (2002).

56. Gawlowski, T. et al. Heat shock protein 27 modification is increased in the human diabetic failing heart. Hormone and metabolic research $=$ Hormon- und Stoffwechselforschung $=$ Hormones et metabolisme 41, 594-599, doi:10.1055/s-00291216374 (2009).

57. Vicente Miranda, H. et al. Heat-mediated enrichment of alpha-synuclein from cells and tissue for assessing posttranslational modifications. Journal of neurochemistry 126, 673-684, doi:10.1111/jnc.12251 (2013).

58. Gomes, R. A. et al. Yeast protein glycation in vivo by methylglyoxal. Molecular modification of glycolytic enzymes and heat shock proteins. Febs J 273, 5273-5287, doi:EJB5520 [pii]

10.1111/j.1742-4658.2006.05520.x (2006).

59. Klionsky, D. J. et al. Guidelines for the use and interpretation of assays for monitoring autophagy (3rd edition). Autophagy 12, 1-222, doi:10.1080/15548627.2015.1100356 (2016).

60. Ardah, M. T. et al. Structure activity relationship of phenolic acid inhibitors of alpha-synuclein fibril formation and toxicity. Front Aging Neurosci 6, 197, doi:10.3389/fnagi.2014.00197 (2014).

61. Daniele, S. G. et al. Activation of MyD88-dependent TLR1/2 signaling by misfolded alpha-synuclein, a protein linked to neurodegenerative disorders. Sci Signal 8, ra45, doi:10.1126/scisignal.2005965 (2015).

62. Fauvet, B. et al. alpha-Synuclein in central nervous system and from erythrocytes, mammalian cells, and Escherichia coli exists predominantly as disordered monomer. J Biol Chem 287, 15345-15364, doi:10.1074/jbc.M111.318949 (2012).

63. Killinger, B. A. \& Moszczynska, A. Characterization of alpha-Synuclein Multimer Stoichiometry in Complex Biological Samples by Electrophoresis. Analytical chemistry 88, 4071-4084, doi:10.1021/acs.analchem.6b00419 (2016).

64. Lazaro, D. F. et al. Systematic comparison of the effects of alpha-synuclein mutations on its oligomerization and aggregation. PLoS Genet 10, e1004741, doi:10.1371/journal.pgen.1004741 (2014).

65. Lee, D., Park, C. W., Paik, S. R. \& Choi, K. Y. The modification of alpha-synuclein by dicarbonyl compounds inhibits its fibril-forming process. Biochimica et biophysica acta 1794, 421-430, doi:10.1016/j.bbapap.2008.11.016 (2009).

66. de Oliveira, R. M. et al. The mechanism of sirtuin 2mediated exacerbation of alpha-synuclein toxicity in models of Parkinson disease. PLoS Biol 15, e2000374, doi:10.1371/journal.pbio.2000374 (2017).

67. Lazaro, D. F., Pavlou, M. A. S. \& Outeiro, T. F. Cellular models as tools for the study of the role of alpha-synuclein in Parkinson's disease. Exp Neurol 298, 162-171, doi:10.1016/j.expneurol.2017.05.007 (2017).

68. Marvian, A. T., Koss, D. J., Aliakbari, F., Morshedi, D. \& Outeiro, T. F. In vitro models of synucleinopathies: informing on molecular mechanisms and protective strategies. Journal of neurochemistry, doi:10.1111/jnc.14707 (2019). 
69. Masaracchia, C. et al. Molecular characterization of an aggregation-prone variant of alpha-synuclein used to model synucleinopathies. Biochim Biophys Acta Proteins Proteom 1868, 140298, doi:10.1016/j.bbapap.2019.140298 (2019).

70. Richard, J. P. Mechanism for the formation of methylglyoxal from triosephosphates. Biochem Soc Trans 21, 549-553 (1993).

71. Aquilina, J. A., Shrestha, S., Morris, A. M. \& Ecroyd, H. Structural and functional aspects of hetero-oligomers formed by the small heat shock proteins alphaB-crystallin and HSP27.

J Biol Chem 288, 13602-13609, doi:10.1074/jbc.M112.443812 (2013).

72. Kudva, Y. C., Hiddinga, H. J., Butler, P. C., Mueske, C. S. \& Eberhardt, N. L. Small heat shock proteins inhibit in vitro $A$ beta(1-42) amyloidogenesis. FEBS letters 416, 117-121 (1997). 73. Lee, S., Carson, K., Rice-Ficht, A. \& Good, T. Small heat shock proteins differentially affect Abeta aggregation and toxicity. Biochemical and biophysical research communications 347, 527-533, doi:10.1016/j.bbrc.2006.06.128 (2006).

74. Yerbury, J. J. et al. The small heat shock proteins alphaBcrystallin and Hsp27 suppress SOD1 aggregation in vitro. Cell stress \& chaperones 18, 251-257, doi:10.1007/s12192-0120371-1 (2013).
75. Oya-Ito, T., Liu, B. F. \& Nagaraj, R. H. Effect of methylglyoxal modification and phosphorylation on the chaperone and anti-apoptotic properties of heat shock protein 27. J Cell Biochem 99, 279-291, doi:10.1002/jcb.20781 (2006).

76. van Heijst, J. W. et al. Argpyrimidine-modified Heat shock protein 27 in human non-small cell lung cancer: a possible mechanism for evasion of apoptosis. Cancer Lett 241, 309319, doi:10.1016/j.canlet.2005.10.042 (2006).

77. Auluck, P. K., Chan, H. Y., Trojanowski, J. Q., Lee, V. M. \& Bonini, N. M. Chaperone suppression of alpha-synuclein toxicity in a Drosophila model for Parkinson's disease. Science 295, 865-868, doi:10.1126/science.1067389 (2002).

78. McLean, P. J. et al. TorsinA and heat shock proteins act as molecular chaperones: suppression of alpha-synuclein aggregation. Journal of neurochemistry 83, 846-854 (2002).

79. Baraibar, M. A. \& Friguet, B. Changes of the proteasomal system during the aging process. Prog Mol Biol Trans/ Sci 109, 249-275, doi:10.1016/B978-0-12-397863-9.00007-9 (2012).

80. Chen, T. S., Richie, J. P., Jr. \& Lang, C. A. The effect of aging on glutathione and cysteine levels in different regions of the mouse brain. Proceedings of the Society for Experimental Biology and Medicine. Society for Experimental Biology and Medicine 190, 399-402 (1989). 
$\begin{array}{lll}\text { A } & \mathrm{MGO}(\mathrm{mM}) & \text { B }\end{array}$

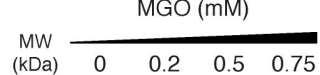

$\begin{array}{ll}27-\square & \text { Argp } \\ & \end{array}$

180

100
70

55

27

35

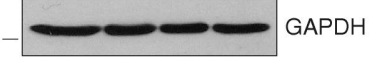

Argp

180 s exp
$\frac{1}{M} \quad 45$

UT TEL

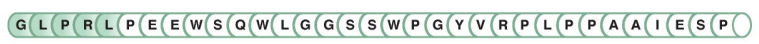

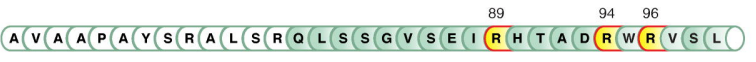

A$$
114
$$

D) VNhHA

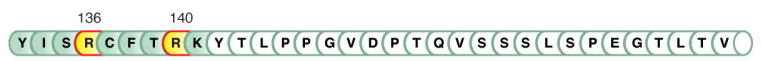

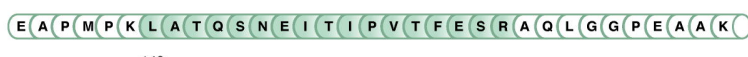

SIDETT(A) 140
Non-covered sequence
Covered sequence
$\bigcirc$ Glycated residue
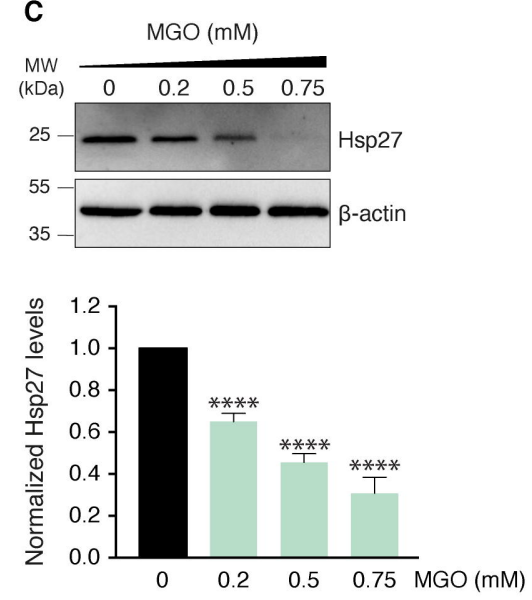

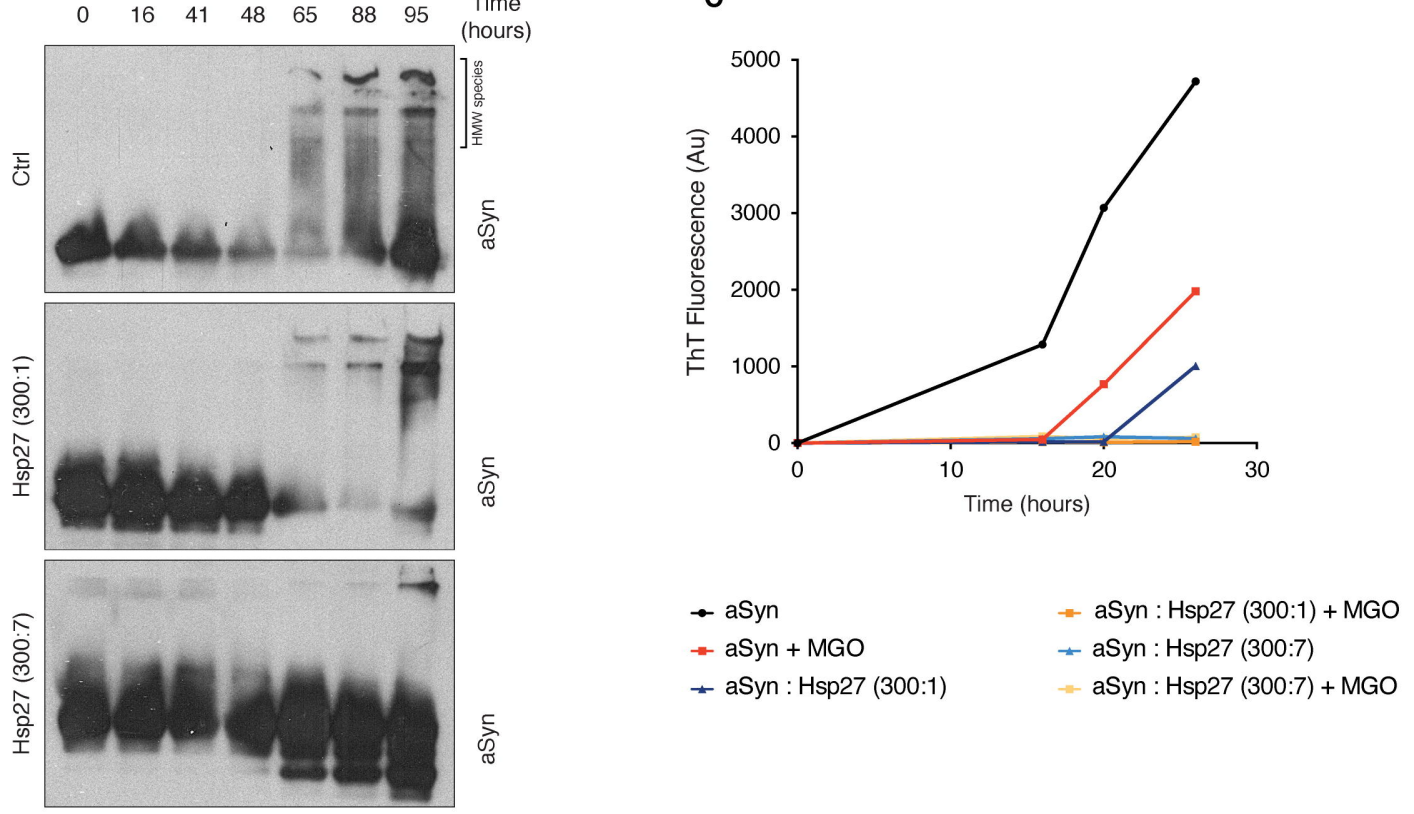

B

MGO

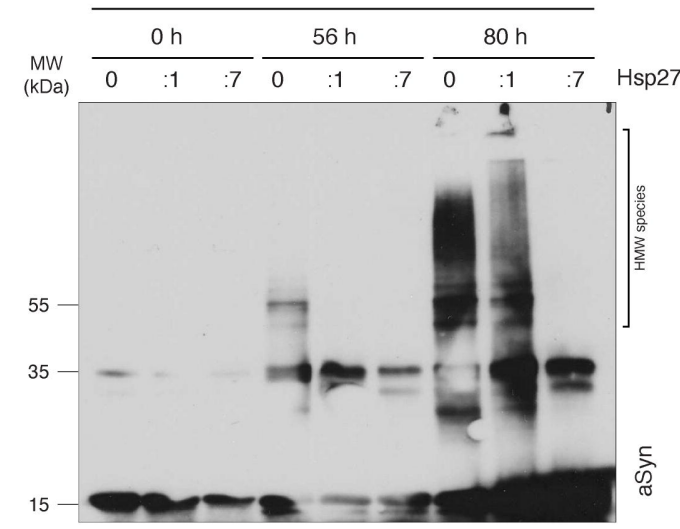

D

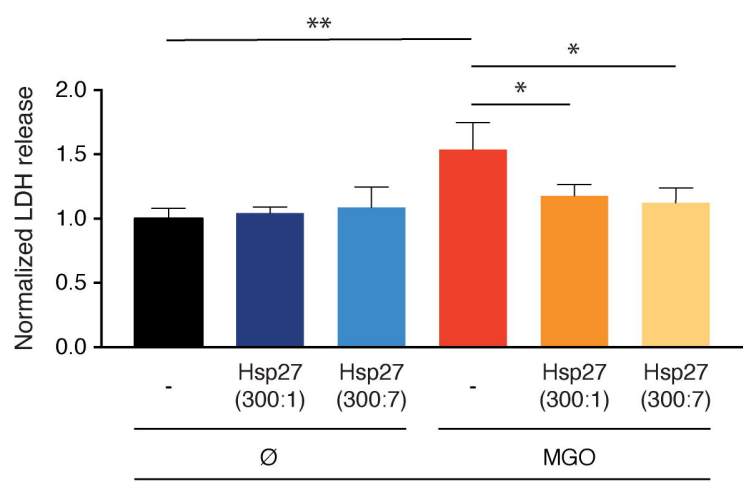

aSyn 

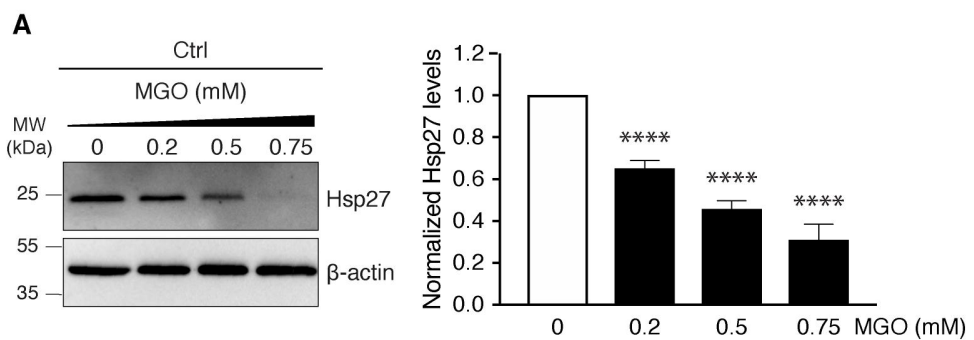

B

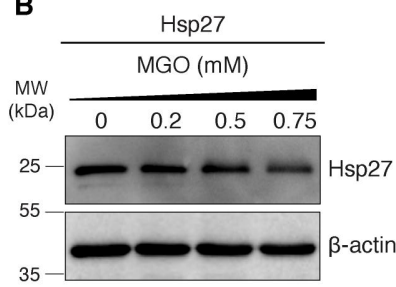

c

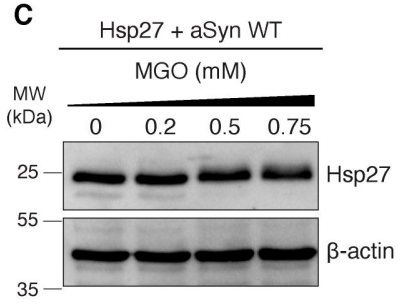

D

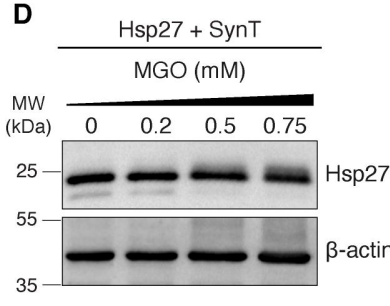

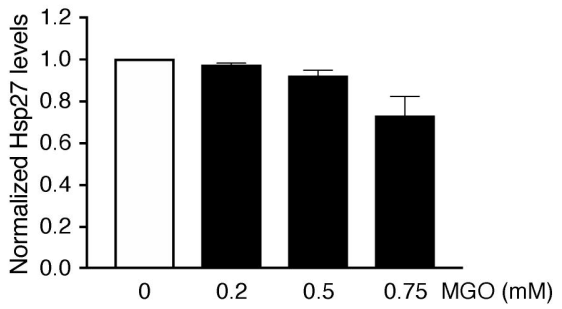
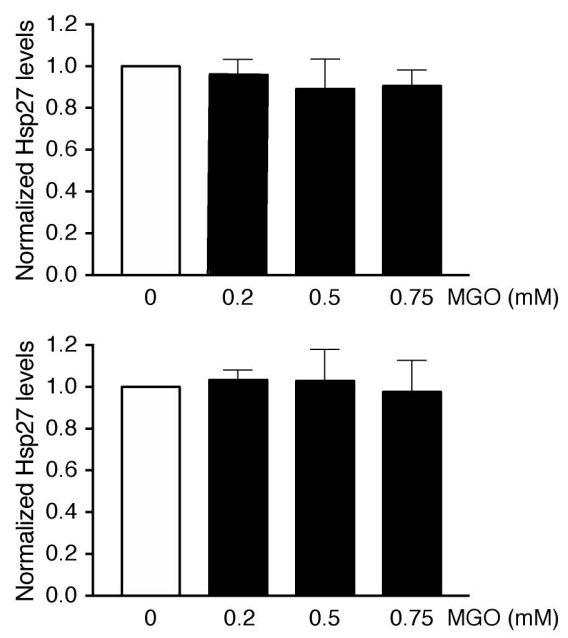

\section{E}

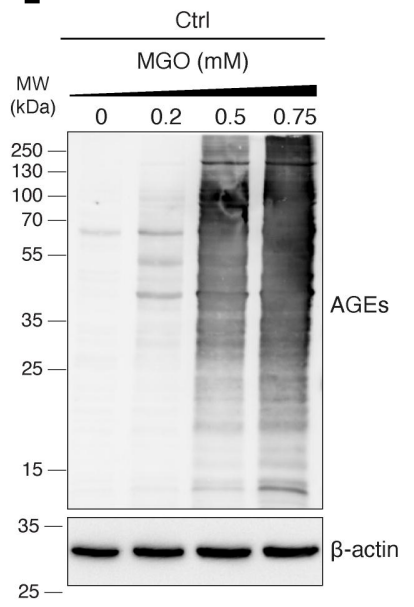

G

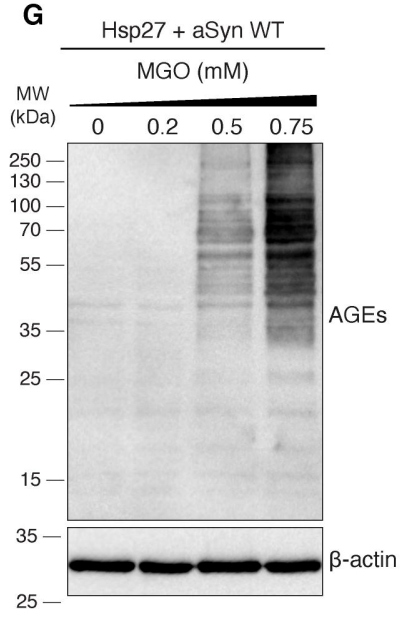

F

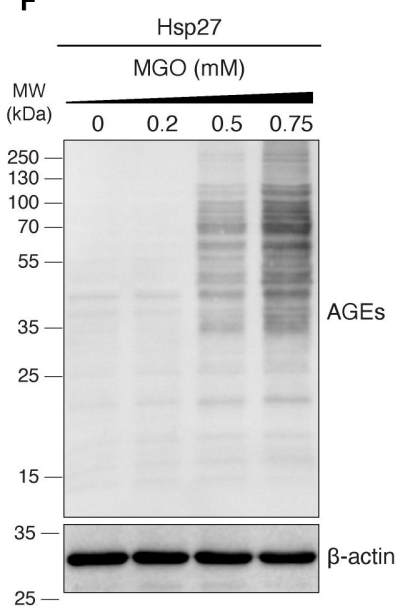

H

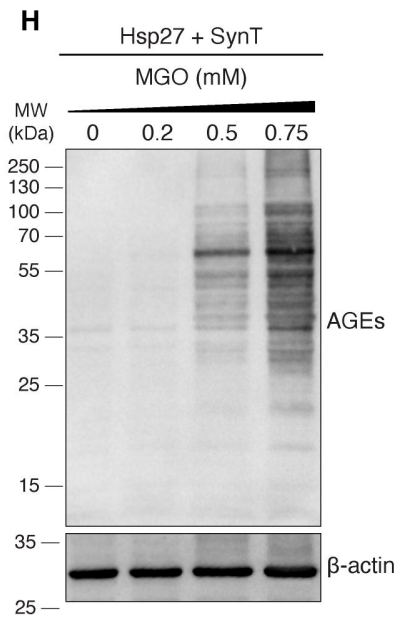



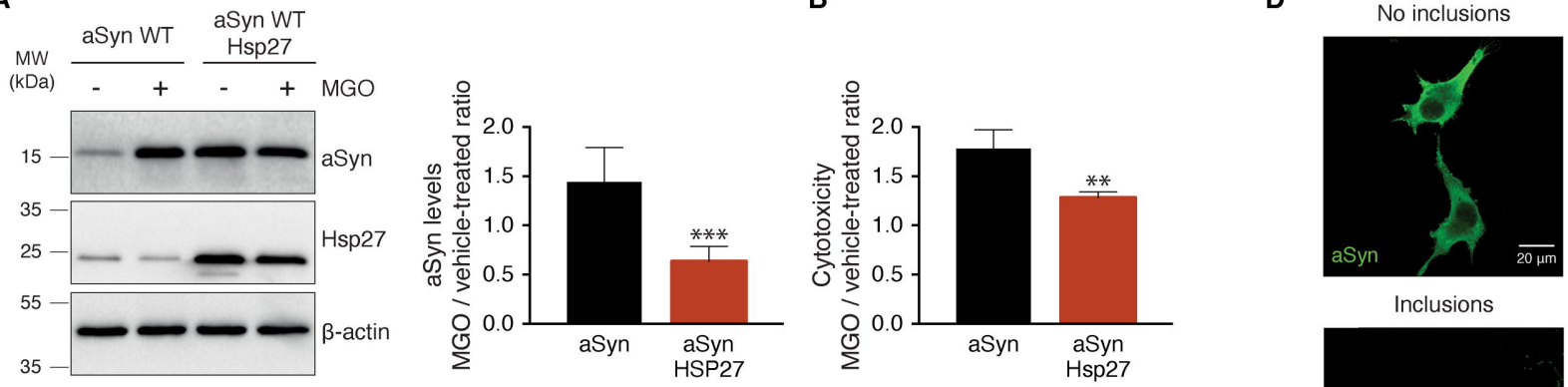

Inclusions
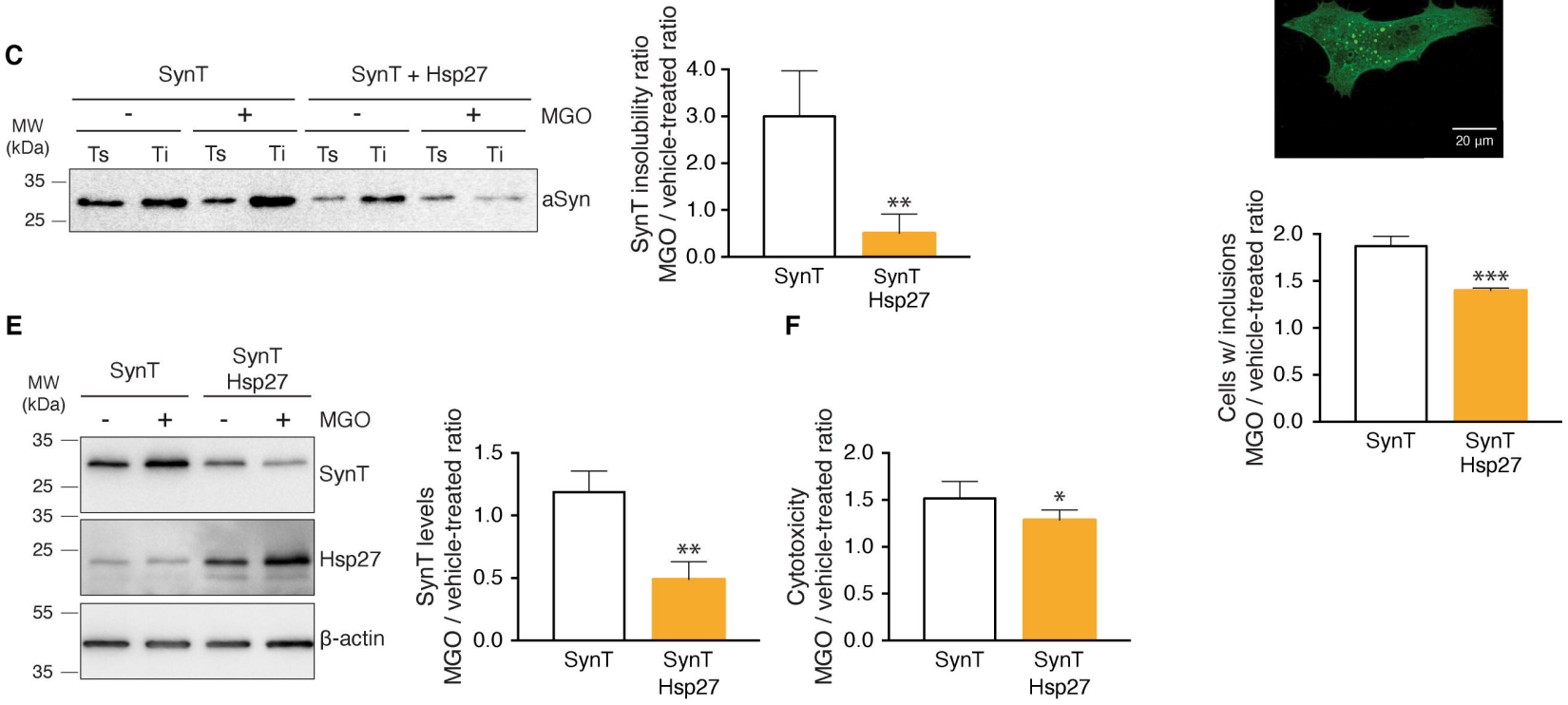


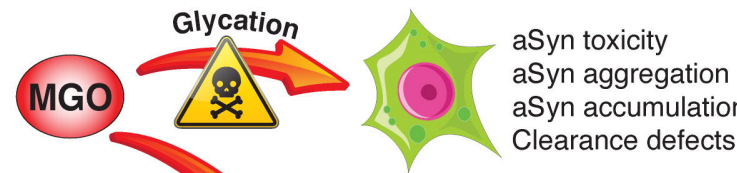

$\geqslant$

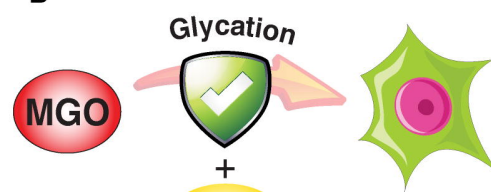

Hsp27
Cytoprotective

Decreases aSyn aggregation

Decreases aSyn accumulation

\section{Hsp27 Decrease}

C

Toxicity

aSyn $\left[\begin{array}{c}\| \\ =d y\end{array}\right]$

Monomers

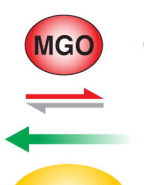

Hsp27

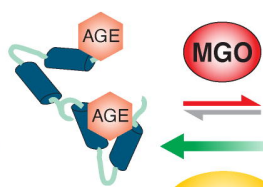

Dimers

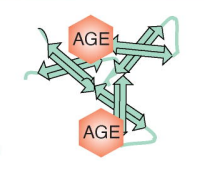

Oligomers

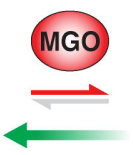

Hsp27

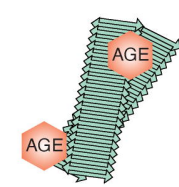

Amyloid fibrils

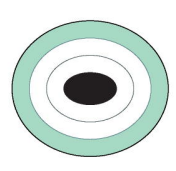

Inclusion bodies 